Pollution Bulletin

Elsevier Editorial System(tm) for Marine

Manuscript Draft

Manuscript Number:

Title: Microplastic Ingestion by Pelagic and Demersal Fish Species from the Eastern Central Atlantic Ocean, off the Coast of Ghana

Article Type: Research Paper

Keywords: Guinea current plastic pollution

Corresponding Author: Dr. Edem Mahu,

Corresponding Author's Institution: University of Ghana

First Author: Stella A Adika

Order of Authors: Stella A Adika; Edem Mahu; Richard Crane; Robert Marchant; Judith Montford; Regina Folorunsho; Christopher Gordon

Abstract: We present data on the occurrence of microplastics in fish from the Guinea current region off Ghana's Coast. Sardinella maderensis had the highest frequency of microplastics (41\%), followed by Dentex angolensis (33\%), then Sardinella aurita (26\%). Mean numbers of microplastics ingested per fish were $31.89 \pm 2.67,25.66 \pm 1.58$ and 39.99 \pm 3.79 for D. angolensis, S. aurita and S. maderensis respectively. Industrially produced pellets were the most dominant (31\%) microplastic type followed by microbeads (29\%), burnt film plastics (22\%) and unidentified fragments (9\%). Microfibers (2\%), threads (2\%) and foams $(<0.1 \%)$ were the least occurring microplastics in the fish species. Condition factors estimated for D. angolensis and S. aurita were greater than 1 and below 1 for $S$. maderensis. The findings of the study show the common occurrence of microplastic in fish stocks and paves the way for future studies on microplastics in this Region.

Suggested Reviewers: Paula Sobral

Faculdade de Ciências e Tecnologia, Universidade Nova de Lisboa psobral@fct.unl.pt

Juan Bellas

Centro Oceanográfico de Vigo, Instituto Español de Oceanografía

juan.bellas@vi.ieo.es 


\title{
Microplastic Ingestion by Pelagic and Demersal Fish Species from the Eastern Central Atlantic Ocean, off the Coast of Ghana
}

\author{
Stella Aseye Adika ${ }^{1}$, Edem Mahu $^{1}$, Richard Crane ${ }^{2}$, Rob Marchant ${ }^{3}$, Judith Montford ${ }^{4}$, Regina \\ Folorunsho ${ }^{5}$ and Christopher Gordon ${ }^{6}$.
}

1. Department of Marine and Fisheries Sciences, University of Ghana

2. College of Engineering, Mathematics and Physical Sciences, University of Exeter

3. York Institute of Tropical Ecosystems, Department of Environment and Geography, University of York, York YO10 5NG, North Yorkshire

4. Scottish Environmental Protection Agency

5. Nigerian Institute of Oceanography and Marine Research

6. Institute of Environment and Sanitation Studies, University of Ghana

*Corresponding Author: emahu@ug.edu.gh

Abstract

We present data on the occurrence of microplastics in fish from the Guinea current region off Ghana's Coast. Sardinella maderensis had the highest frequency of microplastics (41\%), followed by Dentex angolensis (33\%), then Sardinella aurita (26\%). Mean numbers of microplastics ingested per fish were $31.89 \pm 2.67,25.66 \pm 1.58$ and $39.99 \pm 3.79$ for $D$. angolensis, $S$. aurita and $S$. maderensis respectively. Industrially produced pellets were the most dominant (31\%) microplastic type followed by microbeads (29\%), burnt film plastics $(22 \%)$ and unidentified fragments (9\%). Microfibers (2\%), threads $(2 \%)$ and foams $(<0.1 \%)$ were the least occurring microplastics in the fish species. Condition factors estimated for $D$. angolensis and $S$. aurita were greater than 1 and below 1 for $S$. maderensis. The findings of the study show the common occurrence of microplastic in fish stocks and paves the way for future studies on microplastics in this Region.

Keywords: Guinea current plastic pollution

\subsection{Introduction}

The amount of plastic waste generated globally each year is estimated to be approximately 275 megatons (MT), with 4.8 to 12.7 MT ending up in the oceans (Jambeck et al., 2015). Five countries in Africa are among the top 20 plastic waste producers in the world (Jambeck et al., 2018). Ghana generates more than 3000 tonnes of plastic waste daily, with more than 250,000 tonnes of the plastic waste generated dumped into the Atlantic Ocean annually (Effah, 2019). The lack of clean drinking water in some parts of the region exacerbates the problem, because drinking water is packaged in single use sachets and plastic bags in many of the continent's cities (Stoler et al., 2012). It is estimated that 8.2 billion, 7.3 billion and 277.4 million plastic sachets of water are consumed annually in Ghana, Nigeria and Liberia, 
respectively (Wardrop et al., 2017). These three countries generate a total of 28,000 tonnes of plastic waste annually from high-density polyethylene (HDPE) and low-density polyethylene (LDPE) packaging

alone annually (Wardrop et al., 2017). As per the 2015 national population estimates, annual per capita sachet water consumption was 149. 1 in Ghana, 20.01 in Nigeria and 30.91 in Liberia (UNDESA, 2015). The annual per capita consumption in Ghana and Liberia alone are comparable to the 2013 per capita bottle water consumption of 143.0 and 36.5 in the United States and the United Kingdom respectively (BSDA, 2014), therefore, confirming high levels of packaged water consumption in West Africa, and particularly in Ghana. Plastic waste presents not only an environmental issue for African countries but also a major socio-economic development challenge impacting biodiversity, infrastructure, tourism and fisheries livelihoods (Eriksen et al., 2014; UNEP, 2016; Jambeck et al., 2018).

Microplastics, defined as plastic particles $<5 \mathrm{~mm}$ in length, constitute a major component of global marine plastic litter (Arthur et al., 2009; Cole et al., 2011; Rezania et al., 2018). They originate from two main sources; firstly, from the direct emission of microplastic products (e.g. microbeads), and secondly, from breakdown of larger plastic debris (typically via photo-oxidative, chemical or mechanical mechanisms) (Napper et al., 2015; Jambeck et al., 2015). They are are ubiquitous in nature and have been reported across the entire marine environment i.e. from the sea surface to the deepest seabeds (Browne et al., 2011; Liebezeit and Dubaish, 2012; Woodall et al., 2014; Alomar et al., 2016; Suaria et al., 2016; Zhu et al., 2018). They have also been reported to occur in remote habitats of the Arctic and Antarctic oceans (Obbard et al., 2014; Lusher et al., 2015; Isobe et al., 2017). It is estimated that as much as 5 trillion microplastic particles, weighing over 250,000 tons, are currently floating in the global marine environment (Eriksen et al., 2014).

Microplastic ingestion by fish and other marine organisms is an emerging concern due to the risks such particles pose to the health and functioning of marine ecosystems (Lusher, 2015; GESAMP, 2016). Chemical additives used in plastic manufacturing are known to leach into the marine environment and/or directly into biological fluids (e.g. gastrointestinal tract fluids), resulting in potential toxic effects (Rochman et al., 2014). Plastics have also been documented to act as vectors and/or accumulators of contaminants. Given their hydrophobic properties, plastics have also been documented to sorb hydrophobic contaminants and once colonized with biological media they can also become potent sorbents for ecotoxic metals. In addition, plastic particles are known to take up volume in biological systems (e.g. gastrointestinal tracts or blood vessels) and thereby inhibiting their natural functioning (Rochman et al., 2014). The inadvertent consumption of plastics by humans has therefore raised major concerns across the world but in particular in regions, such as East and West Africa, where the consumption of fish components which are likely to be the main recipients of plastic particles (e.g. the gastrointestinal tract) is more common (GESAMP, 2016; Browne et al., 2013; Rochman et al., 2013; Wright et al., 2017). 
Several studies have reported evidence of microplastic ingestion by species of fish, invertebrates, birds and marine mammals from various locations worldwide (e.g., Cole et al., 2011; Lusher

et al., 2013, 2015; Rochman et al., 2015; Terepocki et al., 2017; Fossi et al., 2014). However, a major gap in knowledge relates to the geographic representation of study areas. Available literature shows monitoring studies for microplastics been reported for Europe, Asia, North America and South Africa (Bessa et al., 2018; Allomar et al., 2017; Mizraji et al., 2017; Vendel et al., 2017; Güven et al., 2017; Bellas et al., 2016; Nadal et al., 2016; Lusher et al., 2016; Lusher et al., 2013), with no reported data for the Eastern Central Atlantic, particularly, West Africa. Our study, therefore, presents data on the occurrence of microplastics in three commonly eaten fish species caught from the Eastern Central Atlantic off the coast of Ghana.

\subsection{METHODOLOGY}

\subsection{Study Area.}

Fish specimens were obtained directly from landed boats at the Tema fishing harbor, Accra Ghana (Fig. 1; Lat:5.6667, Long: -0.0167 111 N) between April and May 2019. The harbor attracts close to 400 fishing vessels (including artisanal, industrial and semi industrial) fleeting in the nearshore and offshore areas of the Central Coast of Ghana on daily basis. The coastal zone surrounding the harbor is as regarded one of the most densely marine litter polluted regions in Ghana.

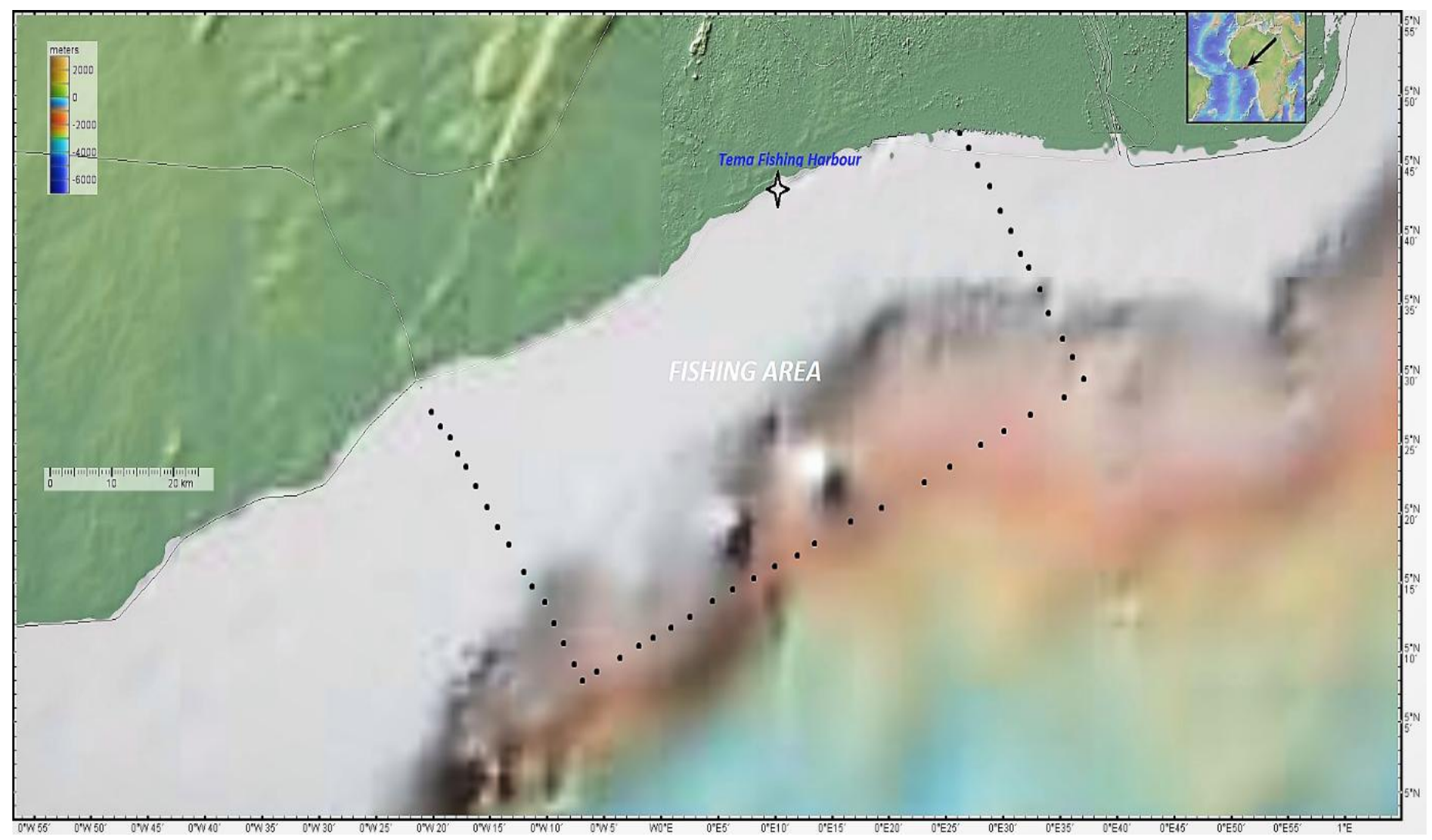

Fig. 1: Map showing fishing area within the Tema Fishing harbor in Ghana 


\subsection{Sample collection}

Fish samples (Sardinella maderensis, Sardinella aurita and Dentex angolensis) were collected from 50 fishing boats using a random sampling approach immediately following landing. A total of 155 fish specimens were obtained for microplastic analysis. Samples were transported on ice and kept frozen until they were ready for analysis at the wet laboratory of the Department of Marine and Fisheries Sciences and the Ecological Laboratory of the University of Ghana. In the laboratory, fish samples were cleaned in microplastic free distilled water to remove any externally adhered plastic as recommended by Lusher et al. (2016).

\subsection{Microplastic Extraction}

Total body length $(\mathrm{cm})$ and body weight $(\mathrm{g})$ were measured for each fish prior to dissection. Fish species were dissected from the anal opening to the head region and their entire gastrointestinal tracts removed (Boerger et al., 2010; Lusher et al., 2016; Bessa et al., 2018). The gastrointestinal tracts were then exposed to $20 \mathrm{~mL}$ of $10 \mathrm{M}$ Potassium hydroxide $(\mathrm{KOH})$ at $60^{\circ} \mathrm{C}$ for 24 hours to ensure their complete digestion, leaving behind only plastic particles, following the methodology outlined by Bessa et al. (2018). Digested fluids samples were then filtered through $1.2 \mu \mathrm{m}$ Whatman GF/C microfiber filter papers and residues dried at $60^{\circ} \mathrm{C}$ for 24 hours prior to identification under the microscope.

\subsection{Observation \& Identification of Microplastics.}

Identification of microplastics were carried out using a Leica EZ4 HD stereo microscope with image analyses system IC80 HD camera. Microplastics particles were counted, classified and categorized by type according to their shape into fibers or threads (elongated), fragments (angular and irregular pieces), film (thin and transparent) and their color (clear or green) following protocols outlined in the Spotter's Guide developed by the Civic Laboratory for Environmental Action Research (CLEAR).

\subsection{Quality Control}

Robust measures were put in place to reduce/avoid microplastic contamination from the working environment. These included maintaining a clean working station, depuration of fish under running filtered water, soaking dissection kits in ethanol between samples to prevent cross contamination, wearing cotton clothing throughout sample preparation and microscopy, setting up petri dishes containing dampened $1.2 \mu \mathrm{m}$ Whatman GF/C microfiber filter papers during sample preparation and microscopy to 
account for airborne contamination and sealing digestion vials and petri dishes between laboratory sessions.

\subsection{Statistical Analysis}

Statistical analyses were performed in PRIMER 6 and Origin 3 statistical software. Results obtained are presented as mean \pm standard error of the mean (SEM). One-way analysis of variance (ANOVA) and Tukey pairwise tests were used in testing differences in means of length, weight and microplastic numbers among the three fish species. Correlation analysis and bivariate plots were performed between fish length and weight, fish length and microplastic numbers and fish weight and microplastic numbers to establish correlation patterns, $r$ and slope (b) values of the fish species.

\subsection{RESULTS}

3.1 Morphometrics and Occurrence of Microplastics (MP) in Fish

D. angolensis, $S$. aurita and $S$. maderensis samples ranged in length from $19.0 \mathrm{~cm}$ to $23.3 \mathrm{~cm}, 21.0 \mathrm{~cm}$ to 25.0 and $13.4 \mathrm{~cm}$ to $27.7 \mathrm{~cm}$ and weighed between $81.0 \mathrm{~g}$ and $194.0 \mathrm{~g}, 86.7 \mathrm{~g}$ and $174.4 \mathrm{~g}, 83.0$ and 154.5 g respectively. Significant difference was observed between the mean length of D. angolensis and $S$. aurita (Tukey's pairwise test; $\mathrm{p}=0.001$ ) and in mean weights among all three fish species (ANOVA; $<<$ 0.05: Tukey's pairwise test; $\mathrm{p}=0.001)$. The length and weight of each species correlated positively (spearman rho $>0.67$ ) yielding a $b$ value of $\sim 3.0$ for all three fish species (Table 1 ).

Table 1. Morphometric parameters and microplastic ingestion values for D. angolensis, $S$. aurita and $S$. maderensis (MPs/individual) from Ghanaian coastal waters

\begin{tabular}{lllllll}
\hline Specie & $\mathbf{n}$ & Length $(\mathbf{c m})$ & Weight $(\mathbf{c m})$ & b & Condition Factor & MPs/Individual \\
\hline D. angolensis & 28 & $20.54 \pm 0.26$ & $134.78 \pm 5.88$ & 2.80 & $1.54 \pm 0.05$ & $31.89 \pm 2.67$ \\
S. aurita & 50 & $22.58 \pm 0.16$ & $117.37 \pm 2.47$ & 2.69 & $1.01 \pm 0.01$ & $25.66 \pm 1.58$ \\
S. maderensis & 77 & $21.70 \pm 0.41$ & $94.47 \pm 4.20$ & 2.69 & $0.88 \pm 0.01$ & $39.99 \pm 3.79$ \\
\hline
\end{tabular}

Condition factors were greater than 1 for D. angolensis and S. aurita and a little below 1 for $S$. maderensis (Table 1). Microplastics were found in the gastrointestinal tracts of all 155 fish samples analyzed with an average of $33.90 \pm 2.10$ particles per total fish. S. maderensis ingested the highest number of microplastic particles $(39.99 \pm 3.79)$, followed by $D$. angolensis $(31.89 \pm 2.67)$ then $S$. aurita $(25.66 \pm 1.58)$ (Table 1$)$. Mean microplastic numbers differed significantly among all three fish species (ANOVA; $\mathrm{P}=0.007$; Tukey's pairwise test; $p<0.05)$. Generally, weak positive correlations were observed between 
microplastic numbers and fish length and weight of S. maderensis, however, the low $\mathrm{R}^{2}$ values of the obtained implied no strong relationship exists between these parameters (Fig. 2).

1
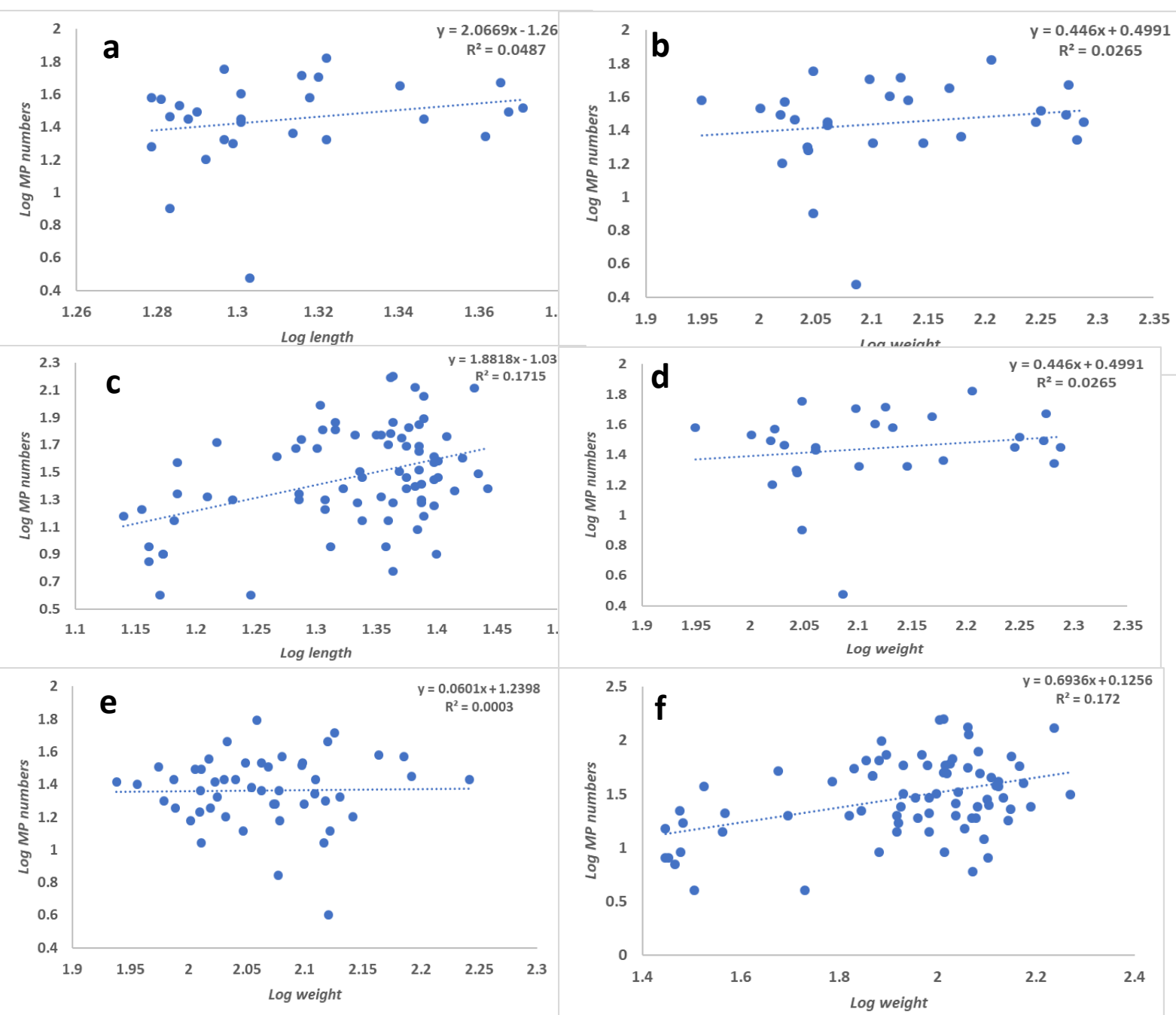

Fig. 2: Bivariate plots of fish length against microplastics numbers $(\mathrm{a}-\mathrm{c} ; \mathrm{a}=D$. angolensis, $\mathrm{b}=$ S.aurita and $\mathrm{c}=S$. maderensis $)$ and fish weight against microplastic numbers $(\mathrm{d}-\mathrm{f} ; \mathrm{d}=D$. angolensis, $\mathrm{e}=S$. aurita and $\mathrm{f}=$ S. maderensis).

\subsection{Microplastic Characterization}

The main types of microplastics found in the gut of the three fish species were fragments, microbeads, films and threads (Fig. 3). Percent composition of plastic types obtained in all 155 fish samples followed the order: industrially produced pellets (IPP; 31\%) > microbeads $(\mathrm{Mb} ; 29 \%)>$ burnt film plastics (BFP, $22 \%)>$ clear plastic fragment (CFP; 6\%) $>$ white plastic fragment (WPF; 3\%) $>$ thread plastics (TP; 2\%) and microfibers (Mf; 2\%) (Fig. 4). 


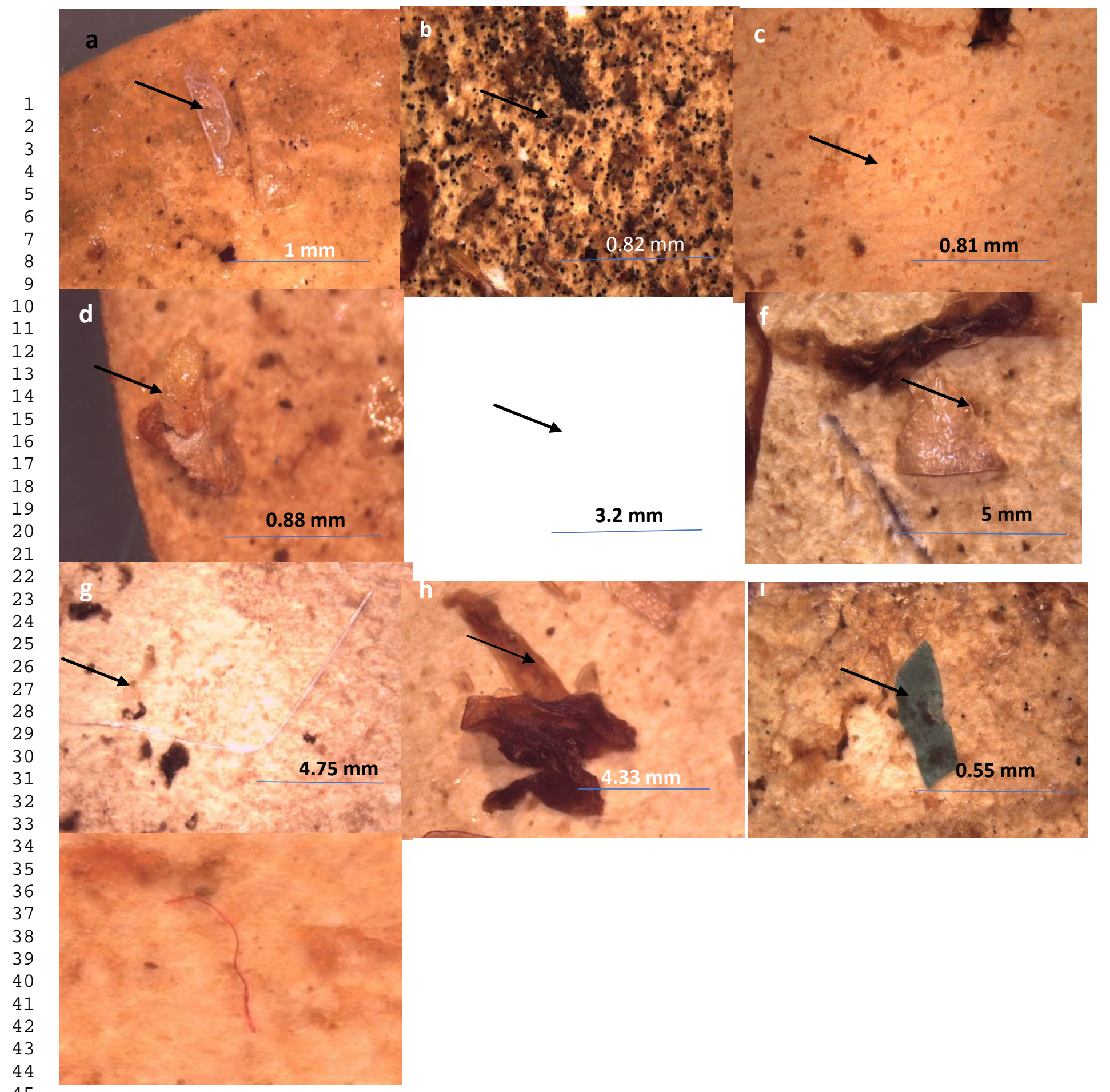

Fig. 3: Examples of microplastics found in D. angolenesis, S. aurita and S. maderensis from Ghanaian coastal waters $(a=$ white plastic fragment, $b=$ microbeads, $c=$ industrially produced pellets, $d=$ plastic foam, $\mathrm{e}=$ clear plastic fragment, $\mathrm{f}=$ plastic thread, $\mathrm{g}=$ burnt plastic film, $\mathrm{h}=$ green plastic fragment, $\mathrm{i}=$ microfiber)

Comparison among fish species showed a higher occurrence of the industrially produced pellets and burnt plastic fragments in S. maderensis relative to D. angolensis and S. aurita while more microbeads were recorded in D. angolensis than S. maderensis and S. aurita (Fig. 5). Although micro fibers, thread plastics and foam plastics were the least occurring plastics, their occurrences were relatively higher in $S$. 
maderensis for microfibers, and S. aurita for both thread and foam plastics (Fig. 5). White and green fragments were generally higher in $S$. maderensis clear fragments were higher in $D$. angolensis.

1

2

3

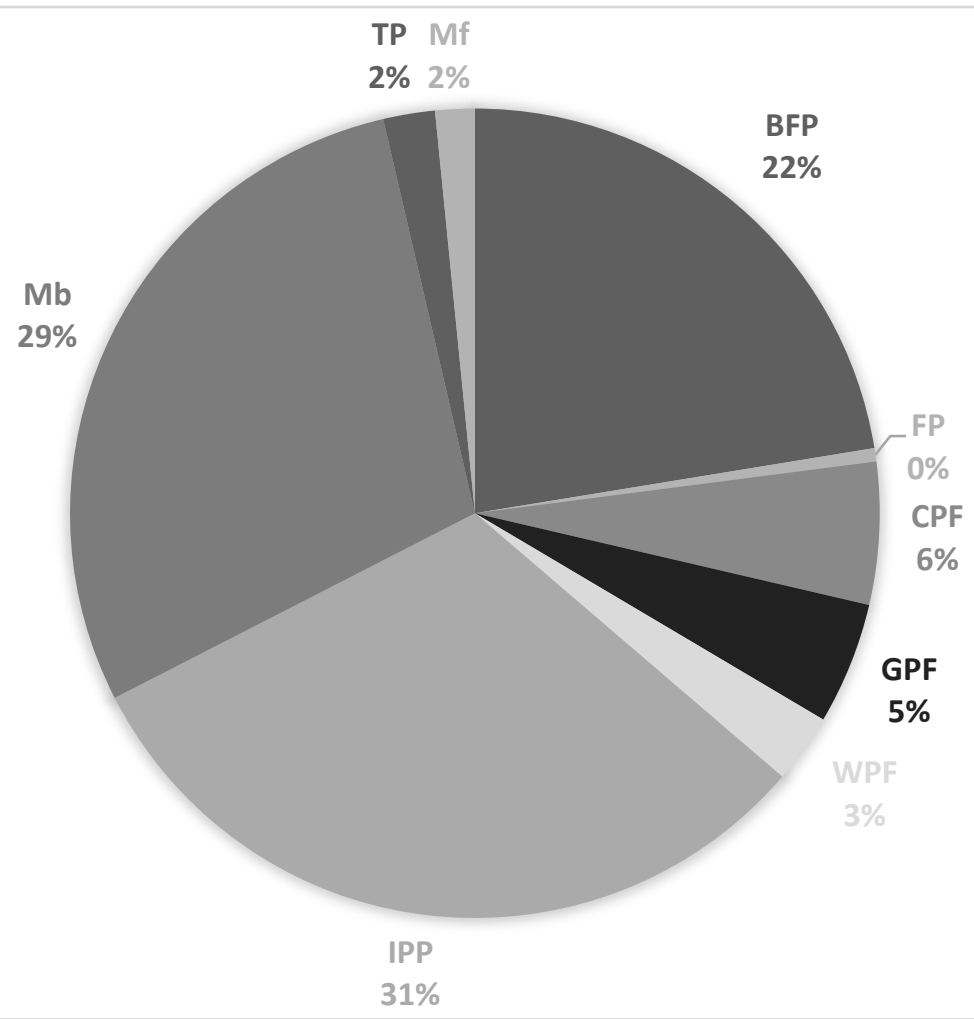

Fig. 4: Total microplastic composition in fish from Ghanaian coastal waters based on extractions performed on $D$. angolensis, $S$. aurita and $S$. maderensis. $(\mathrm{Mf}=$ microfiber, $\mathrm{TP}=$ thread plastic, $\mathrm{Mb}=$ microbeads, IPP $=$ industrially produced pellets, $\mathrm{WPF}=$ white plastic fragment, $\mathrm{GPF}=$ green plastic fragment, $\mathrm{CPF}=$ clear plastic fragment, $\mathrm{FP}=$ foam plastic, $\mathrm{BFP}=$ burnt plastic film) 
Fig. 5: Types of microplastics detected in D. angolensis, S. aurita and S. maderensis caught from Ghanaian coastal waters. $(\mathrm{Mf}=$ microfiber, $\mathrm{TP}=$ thread plastic, $\mathrm{Mb}=$ microbeads, $\mathrm{IPP}=$ industrially produced pellets, $\mathrm{WPF}=$ white plastic fragment, $\mathrm{GPF}=$ green plastic fragment, $\mathrm{CPF}=$ clear plastic fragment, $\mathrm{FP}=$ foam plastic, $\mathrm{BFP}=$ burnt plastic film)

\subsection{DISCUSSION}

Microplastics were determined as present in the gastrointestinal tract of all three fish species studied. microplastic occurrence in the gut of the studied fish species was found to be frequent with $S$. maderensis ingesting the highest amount of plastic debris and $S$. aurita ingesting the least. This high occurrence of microplastics in the gut of S. maderensis and D. angolensis could be related to the fact that both species most commonly reside in coastal regions (Koranteng, 1996; Troadec and Garcia, 1980), where the influx of plastic debris is more significant than deeper regions. High microplastic ingestion rates in S. maderensis relative to $S$. aurita can be linked to the distribution and movement patterns of the two species. S. maderensis is a coastal, mostly euryhaline fish, often abundant near water course outlets with adults confined over the shallow half of the continental shelf to about $50 \mathrm{~m}$ water depth (Troadec and Garcia, 1980). S. aurita prefers saline marine waters with adults wintering in water depths beyond $50 \mathrm{~m}$, moving closer to shallower waters only when the upwelling season commences (typically in July), thereafter, returning to winter in deeper waters by the winter (Ansa-Emmim, 1973). This sedentary nature of the $S$. maderensis relative to $S$. aurita means it spends more time in coastal waters.

High ingestion of microbeads was recorded for $D$. angolensis whereas high ingestion of plastic films, fibers and threads were recorded for S. maderensis and S. aurita. This could be linked to the fact 
that $D$. angolensis most commonly feed at the sediment-water interface (Koranteng 1996) while $S$. maderensis and S. aurita are both pelagic feeders (Morote et al., 2008). As such, the lower surface area to

volume ratios of the former materials dictates that they are more likely to sink into the benthic environment compared to the greater surface area to volume ratios of the latter materials which are more likely to float on or within the water column (Li et al., 2018).

Microbeads, pellets and burnt films are prevalent in this study relative to fibers which have been reported as widely occurring in most studies (Table 2). The exact source of microbeads and pellets in this study remains unclear, however, the reported high occurrences may be related to input from discrete point sources such as plastic processing plants where the abundance of plastic pellets or powders can be considerable, factories and sewage discharges, transport at sea and offload from shipping terminals (Norén and Ekendahl, 2009). The rise in the consumption of plastic sachet water and widespread use of polyethylene bags for shopping in the West African sub-region may be linked to the reported abundances in burnt films. Plastic sachet water bags form the major constitute of marine litter in Ghana (Tsagbey, 2009), hence, it is not surprising this study found burnt plastic films to be a dominant microplastic in all three fish species.

Microfibres are among the most prevalent type of microplastics observed in the marine environment (Bessa et al., 2018; Allomar et al., 2017; Mizraji et al., 2017; Vendel et al., 2017; Güven et al., 2017; Bellas et al., 2016; Nadal et al., 2016; Lusher et al., 2016; Lusher et al., 2013) yet, they have been reported to be least occurring in all three fish species studied. As washing of clothes in washing machine is the main route of synthetic fibers into the coastal environment, we attribute the low numbers in this study to the relatively low patronage of washing machines in the West African sub-region. Until the last 10 years, over $90 \%$ of households washed their clothes by hand, which does not shed any significant amount of synthetic fibers into the environment. It is however anticipated that microfibers may become a major issue in the Gulf Guinea in the coming years since washing machines are now becoming popular in many households.

Despite the high microplastic ingestion rates however, the values of the growth coefficient (b) was approximately equal 3, indicating an isometric growth, i.e. length and weight are growing at approximately the same rate (Beverton and Holt, 1996). Although no relationship was observed in fish condition factors and microplastic ingestion, condition factors were greater than 1 in D. angolensis and $S$. aurita and below 1 in $S$. maderensis implying healthy conditions in D. angolensis and S. aurita and relatively poorer health in $S$. maderensis. The relatively lesser condition factor in $S$. maderensis may be related to high ingestion rates reported in this study for this specie, however we caution that condition factor may be affected by several environmental factors (Parrish and Mallicoate, 1995) which this study did not account for. Foekema et al. (2013) reported no significant relationship between plastic ingestion and overall condition of various fish species from the North Sea, arguing that the numbers of particles 
ingested were too small to cause feelings of satiation, intestinal blockage. Alomar et al. (2017) found no evidence of oxidative stress or cellular damage in the liver of red mullet, Mullus surmuletus upon

ingestion of microplastics, although a small increase in the activity of glutathione S-transferase (GST) of was detected which could be suggesting an induction of the detoxification systems. More studies therefore need to be conducted to understand and relate microplastic ingestion to fish and human health.

\subsection{Conclusions}

The results of the study depict high microplastic ingestion rates in fish particularly, $S$ maderensis from the coastal waters of Ghana in the Gulf of Guinea, mainly, from microbeads, pellets and burnt plastic films. Although we are unable to account for the source of pellets, we anticipate their occurrence may be tied to shipping operations. In contrast to most studies conducted in Europe and America, our study found synthetic fibers to be the least occurring microplastics. We attribute the high occurrences of burnt films to the extremely high consumption rates of sachet water in the sub-region. Despite having high ingestion values, the estimated condition factors suggest $D$. angolensis and $S$. aurita are in good health. The condition factor of S. maderensis was however below 1, implying poorer physiological wellbeing. We relate this to the rather sedentary coastal nature of this species, implying it is likely to spend more time in polluted region than the other two dish species.

\section{Acknowledgement}

The authors acknowledge full financial support from Global Challenges Research Fund (GCRF) through its networking grant \# GCRFNGR2_10334 awarded to the University of Ghana and the University of Exeter. We also acknowledge field and laboratory support of Mr. Charles Mario Boateng during the project.

\section{References}

Alomar, C., Estarellas, F., \& Deudero, S. (2016). Microplastics in the Mediterranean Sea: deposition in coastal shallow sediments, spatial variation and preferential grain size. Marine environmental research, 115, 1-10.

Ansa-Emmim, M. (1973). Pelagic Fisheries, pp 42-46 In the Ghana Fishing Industry. Proceedings of Symposium on the Fishing Industry in Ghana, May 4-5, 1972. Fishery Research Unit, Tema

Arthur, C., Baker, J., \& Bamford, H. (2009). Proceedings of the International Research Workshop on the Occurrence, Effects, and Fate of Microplastic Marine Debris, September 9-11, 2008. 
Bellas, J., Martínez-Armental, J., Martínez-Cámara, A., Besada, V., \& Martínez-Gómez, C. (2016). Ingestion of microplastics by demersal fish from the Spanish Atlantic and Mediterranean coasts. Marine pollution bulletin, 109(1), 55-60.

Bessa, F., Barría, P., Neto, J. M., Frias, J. P., Otero, V., Sobral, P., \& Marques, J. C. (2018). Occurrence of microplastics in commercial fish from a natural estuarine environment. Marine pollution bulletin, 128, 575-584.

Beverton, R.J.H. and Holt, S.J. (1996). On the Dynamics of Exploited Fish Populations. Chapman and Hall, London, 533 pp.

Beverton, R.J.H., and Holt, S.J. 1959. A review of the lifespans and mortality rates of fish in nature and the relation to growth and other physiological characteristics. Ciba Found. Colloq. Ageing, 5: 142-177.

Boerger, C. M., Lattin, G. L., Moore, S. L., \& Moore, C. J. (2010). Plastic ingestion by planktivorous fishes in the North Pacific Central Gyre. Marine pollution bulletin, 60 (12), 2275-2278.

British Soft Drinks Association (BSDA). 2014. Creating new choices: the 2014 UK soft drinks report (http://www.britishsoftdrinks.com/write/mediauploads/bsda_annual_report_2014.pdf)

Browne, M. A., Niven, S. J., Galloway, T. S., Rowland, S. J., \& Thompson, R. C. (2013). Microplastic moves pollutants and additives to worms, reducing functions linked to health and biodiversity. Current Biology, 23(23), 2388-2392.

Cole, M., Lindeque, P., Halsband, C., \& Galloway, T. S. (2011). Microplastics as contaminants in the marine environment: a review. Marine pollution bulletin, 62(12), 2588-2597.

Dehaut, A., Cassone, A.L., Frère, L., Hermabessiere, L., Himber, C., Rinnert, E., Rivière, G.,Lambert, C., Soudant, P., Huvet, A., Duflos, G., Paul-Pont, I.,(2016). Microplastics inseafood: benchmark protocol for their extraction and characterization. Environ.Pollut. 215, 223-233. http://dx.doi.org/10.1016/j.envpol.2016.05.018.

Effah, K. (2019). US Embassy laments Ghana's inability to recycle plastic waste. https://yen.com.gh/126591-us-embassy-laments-ghana.html\#126591. Retrieved 21/08/2019

Eriksen M, Lebreton LCM, Carson HS, Thiel M, Moore CJ, et al. (2014). Plastic pollution in the world's oceans: more than 5 trillion plastic pieces weighing over 250,000 tons afloat at sea. PLOS ONE 9:e111913

Fossi, M. C., Coppola, D., Baini, M., Giannetti, M., Guerranti, C., Marsili, L., \& Clò, S. (2014). Large filter feeding marine organisms as indicators of microplastic in the pelagic environment: the case studies of the Mediterranean basking shark (Cetorhinus maximus) and fin whale (Balaenoptera physalus). Marine environmental research, 100, 17-24.

Güven, O., Gökdağ, K., Jovanović, B., \& Kıdeyş, A. E. (2017). Microplastic litter composition of the Turkish territorial waters of the Mediterranean Sea, and its occurrence in the gastrointestinal tract of fish. Environmental Pollution, 223, 286-294.

Hermsen, E., Pompe, R., Besseling, E., \& Koelmans, A. A. (2017). Detection of low numbers of microplastics in North Sea fish using strict quality assurance criteria. Marine pollution bulletin, 122(1-2), 253-258.

Isobe, A., Uchiyama-Matsumoto, K., Uchida, K., Tokai, T., (2017). Microplastics in the Southern Ocean. Mar. Pollut. Bull. 114, 623-626. http://dx.doi.org/10.1016/j.marpolbul.2016.09.037. 
Jambeck, J., Hardesty, B. D., Brooks, A. L., Friend, T., Teleki, K., Fabres, J., ... \& Baleta, T. (2018).

Challenges and emerging solutions to the land-based plastic waste issue in Africa. Marine Policy, 96, 256263.

Jambeck, J. R., Geyer, R., Wilcox, C., Siegler, T. R., Perryman, M., Andrady, A., ... \& Law, K. L. (2015). Plastic waste inputs from land into the ocean. Science, 347(6223), 768-771.

Kershaw, P. J., \& Rochman, C. M. (2015). Sources, fate and effects of microplastics in the marine environment: part 2 of a global assessment. Reports and studies-IMO/FAO/UnescoIOC/WMO/IAEA/UN/UNEP Joint Group of Experts on the Scientific Aspects of Marine Environmental Protection (GESAMP) eng no. 93.

Koranteng, K. A. (1996). The marine artisanal fishery in Ghana: Recent developments and implications for resource evaluation. In Fisheries Resource Utilization and Policy. Proceedings of the World Fisheries Congress, Theme (Vol. 2, pp. 498-509).

Kühn, S., van Werven, B., van Oyen, A., Meijboom, A., Bravo Rebolledo, E.L., vanFraneker, J.A., (2017). The use of potassium hydroxide $(\mathrm{KOH})$ solution as a suitableapproach to isolate plastics ingested by marine organisms. Mar. Pollut. Bull. 115,86-90.

Li, L. Deng, M. H., Cai, L., Cai, H., Yan, B., Hu, J. and Shi, H. (2018). A straightforward method for measuring the range of apparent density of microplastics. Science of the Total Environment 639 (2018) $367-373$.

Liebezeit, G., Dubaish, F., (2012). Microplastics in beaches of the East Frisian Islands Spiekeroog and Kachelotplate. Bull. Environ. Contam. Toxicol. 89, 213-217.

Lusher, A. (2015). Microplastics in the marine environment: distribution, interactions and effects. In Marine anthropogenic litter (pp. 245-307). Springer, Cham.

Lusher, A. L., Mchugh, M., \& Thompson, R. C. (2013). Occurrence of microplastics in the gastrointestinal tract of pelagic and demersal fish from the English Channel. Marine pollution bulletin, 67(1-2), 94-99.

Lusher, A.L., O'Donnell, C., Officer, R., O'Connor, I., (2016). Microplastic interactions with North Atlantic mesopelagic fish. ICES J. Mar. Sci. 73, 1214-1225. http://dx.doi.org/10.1093/icesjms/fsv241.

Mizraji, R., Ahrendt, C., Perez-Venegas, D., Vargas, J., Pulgar, J., Aldana, M., ... \& Galbán-Malagón, C. (2017). Is the feeding type related with the content of microplastics in intertidal fish gut?. Marine pollution bulletin, 116(1-2), 498-500.

Morote, E., Olivar, M.P., Villate, F., and Uriarte, I. (2008). Diet of round sardinella, Sardinella aurita, larvae in relation to plankton availability in the NW Mediterranean. Journal of Plankton Research, 30 (7): $807-816$.

Nadal, M. A., Alomar, C., \& Deudero, S. (2016). High levels of microplastic ingestion by the semipelagic fish bogue Boops boops (L.) around the Balearic Islands. Environmental pollution, 214, 517-523.

Napper, I.E., Bakir, A., Rowland, S.J., Thompson, R.C., (2015). Characterisation, quantity and sportive properties of microplastics extracted from cosmetics. Mar. Pollut. Bull. 99, 178e185.

Norén, F., \& Ekendahl, S. (2009). Microscopic Anthropogenic Particles in Swedish Waters: many more than believed. Schwerin, Germany: Helsinki Commission. 
Obbard, R. W., Sadri, S., Wong, Y. Q., Khitun, A. A., Baker, I., \& Thompson, R. C. (2014). Global warming releases microplastic legacy frozen in Arctic Sea ice. Earth's Future, 2(6), 315-320.

Parrish, R.H., and Mallicoate, D.L. (1995). Variation in the condition factors of California pelagic fishes and associated environmental factors. Fish

Rezania, S., Parka, J., Din, M.F.M., Taib, S.M., Talaiekhozani, A., Yadav, K.K., Kamyabe, H., (2018). Microplastics pollution in different aquatic environments and biota: a re-view of recent studies. Mar. Pollut. Bull. 133, 191-208.

Rochman, C. M. (2015). The complex mixture, fate and toxicity of chemicals associated with plastic debris in the marine environment. In Marine anthropogenic litter (pp. 117-140). Springer, Cham.

Rochman, C. M., Browne, M. A., Halpern, B. S., Hentschel, B. T., Hoh, E., Karapanagioti, H. K.,\& Thompson, R. C. (2013). Policy: Classify plastic waste as hazardous. Nature, 494(7436), 169.

Rochman, C. M., Hoh, E., Kurobe, T., \& Teh, S. J. (2013). Ingested plastic transfers hazardous chemicals to fish and induces hepatic stress. Scientific reports, 3, 3263.

Rochman, C. M., Kurobe, T., Flores, I., \& Teh, S. J. (2014). Early warning signs of endocrine disruption in adult fish from the ingestion of polyethylene with and without sorbed chemical pollutants from the marine environment. Science of the Total Environment, 493, 656-661.

Stoler, J., Weeks, J. R., \& Fink, G. (2012). Sachet drinking water in Ghana's Accra-Tema metropolitan area: past, present, and future. Journal of Water, Sanitation and Hygiene for Development, 2(4), 223-240.

Suaria, G., Avio, C. G., Mineo, A., Lattin, G. L., Magaldi, M. G., Belmonte, G., ... \& Aliani, S. (2016). The Mediterranean Plastic Soup: synthetic polymers in Mediterranean surface waters. Scientific reports, 6 , 37551.

Tsagbey S.A., Mensah, A.M., and Nunoo, F.K.E. (2009). Influence of Tourist Pressure on Beach Litter and Microbial Quality - Case Study of Two Beach Resorts in Ghana. West African Journal of Applied Ecology 15: 1-8.

Terepocki, A.K., Brush, A.T., Kleine, L.U., Shugart, G.W., Hodum, P., 2017. Size and dynamics of microplastic in gastrointestinal tracts of Northern Fulmars (Fulmarusglacialis) and Sooty Shearwaters (Ardenna grisea). Mar. Pollut. Bull. 116, 143-150.http://dx.doi.org/10.1016/j.marpolbul.2016.12.064.

Troadec, J. P., \& Garcia, S. (1980). The fish resources [incl. shrimps] of the eastern central Atlantic. Pt. 1: The resources of the Gulf of Guinea from Angola to Mauritania. Rome (Italy). Fishery Resources and Environment Div. FAO FIR. http://agris.fao.org/agrissearch/search.do?recordID=XF19810648745. Retrieved 22/08/2019.

United Nations Department of Economic and Social Affairs (UNDESA). (2015). World Population Prospects (http://esa.un.org/unpd/wpp/DataQuery/) (Accessed: 26 April 2016)

United Nations Environment Programme. (2014). Plastic waste causes financial damage of US\$13 billion to marine ecosystems each year as concern grows over microplastics. [Cited 2016 December 11]. http://www.unep.org/newscentre/default.aspx?DocumentiD1/42791 \&articleiD1/410903

Vendel, A. L., Bessa, F., Alves, V. E. N., Amorim, A. L. A., Patrício, J., \& Palma, A. R. T. (2017). Widespread microplastic ingestion by fish assemblages in tropical estuaries subjected to anthropogenic pressures. Marine pollution bulletin, 117(1-2), 448-455. 
Wardrop, A.N; Dzodzomenyo, M.; Aryeetey, G.; Hill A.G.; Bain, E.R.S and Wright, J. (2017). Estimation of packaged water consumption and associated plastic waste production from household budget surveys Environ. Res. Lett. 12074029

Woodall, L. C., Sanchez-Vidal, A., Canals, M., Paterson, G. L., Coppock, R., Sleight, V., ... \& Thompson, R. C. (2014). The deep sea is a major sink for microplastic debris. Royal Society open science, 1(4), 140317.

Wright, S. L., \& Kelly, F. J. (2017). Plastic and human health: a micro issue? Environmental science \& technology, 51(12), 6634-6647.

Zhu, L., Bai, H., Chen, B., Sun, X., Qu, K., \& Xia, B. (2018). Microplastic pollution in North Yellow Sea, China: Observations on occurrence, distribution and identification. Science of the Total Environment, 636, 20-29. 


\section{Declaration of interests}

$\bigotimes$ The authors declare that they have no known competing financial interests or personal relationships that could have appeared to influence the work reported in this paper.

$\square$ The authors declare the following financial interests/personal relationships which may be considered as potential competing interests:

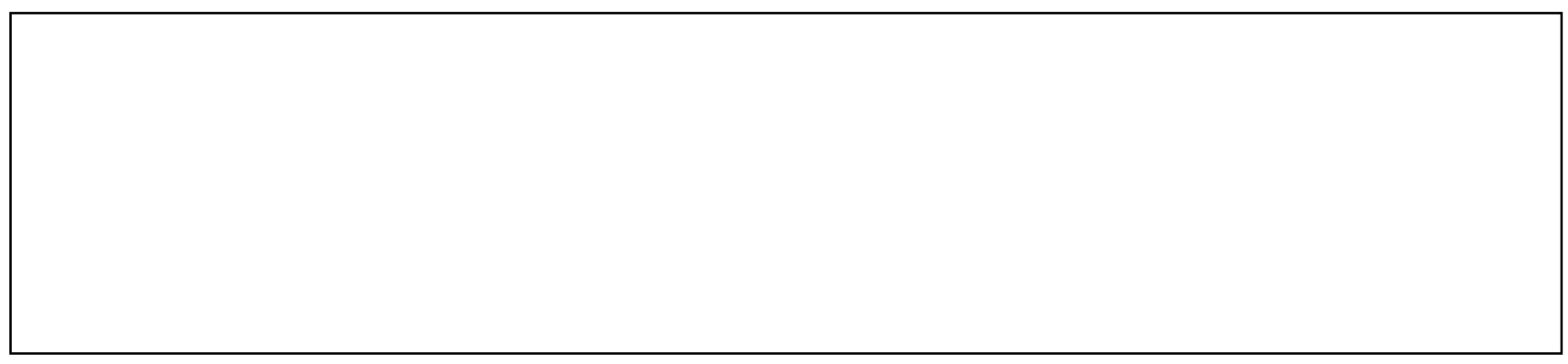

